\title{
Determination of the main spectral characteristics and conditions for the extraction of the cationic dye pyronine $G$ with higher carboxylic acids
}

\author{
(C) Viachaslau U. Zhylko, ${ }^{1,2} *^{+}$and Natalia V. Nekhan ${ }^{1,3}$ \\ ${ }^{1}$ Belarusian State University. Nezavisimosti Ave., 4. Minsk, 220030. Republic of Belarus. \\ ${ }^{2}$ International Sakharov Environmental Institute Named after of Belarusian State University. \\ Dolgobrodskaya St., 23. Minsk, 220070. Republic of Belarus. \\ ${ }^{3}$ Belarusian State Pedagogical University Named after Maxim Tank. Sovetskaya St., 18. \\ Minsk, 220050. Republic of Belarus.E-mail: zhylko@tut.by
}

\begin{abstract}
*Supervising author; ${ }^{+}$Corresponding author
Keywords: extraction; pyronine G; extraction-photometric determination; carboxylic acids; cationic dyes.
\end{abstract}

\begin{abstract}
The selection of the suitable cationic dye is one of the key steps in extraction-photometric methods for the quantitative determination of hydrophobic anions, in particular, higher carboxylic acids. No less important is the reasonable selection of the required polar phase $\mathrm{pH}$ for extraction systems. It is because higher carboxylic acids are well extracted by non-polar phase in molecular form. It was found that, in contrast to other cationic dyes, pyronine $\mathrm{G}$, which is stable in high alkaline $\mathrm{pH}$ values, is well extracted in form of ionic associates with higher carboxylic acids. The optimal composition of organic phase $(5 \%$ solution by volume of $n$-octanol-1 in heptane) was found for quantitative analysis of higher carboxylic acids in the form of associates with pyronine $\mathrm{G}$, at which the blank sample has a rather low optical density.

Molar extinction coefficient of dyes for quantitative photometric analysis is an equally important characteristic of their optical properties. These properties depend on not only the nature of the substance itself, but also on the solvent. The molar extinction coefficients for organic $\left(5.3 \cdot 10^{4} 1 \cdot \mathrm{mol}^{-1} \cdot \mathrm{cm}^{-1}\right)$ and aqueous phases $\left(3.6 \cdot 10^{4} 1 \cdot \mathrm{mol}^{-1} \cdot \mathrm{cm}^{-1}\right)$ were determined for the above-found optimal extraction system for pyronine $\mathrm{G}$ with palmitic acid (water - 5\% solution by volume of $n$-octanol-1 in heptane). They are 1.5-2 times higher than the molar extinction coefficients of safranin $\mathrm{T}$ and other cationic dyes used in the photometric analysis of hydrophobic acids in high alkaline $\mathrm{pH}$ values.

Thus, the cationic dye pyronine $\mathrm{G}$ use for quantitative extraction-photometric analysis of higher carboxylic acids seems to be very promising.
\end{abstract}

\section{References}

[1] V.U. Zhylko, N.V. Klimashevich. Experimental selection of cationic dyes stable in a strongly alkaline medium for the extraction-photometric determination of hydrophobic carboxylic acids. Student science the innovative potential of the future: Art. int. student forum. science, Minsk, 18-27 Apr. 2018. Belarus. state ped. un-t; editorial board: A. V. Torkhova [and others]. Minsk. 2018. P.165-168.

[2] V.U. Zhylko, N.V. Klimashevich. Selection of conditions for quantitative extraction-photometric determination of higher carboxylic acids with a cationic dye Pironin G. Actual problems of chemistry: research and prospects: materials of the Third All-Ukrainian. scientific. conf., Zhitomir, March 16, 2019. Zhitomer. state un-t; editorial board: N. V. Kusyak [et al.]. Zhitomir. 2019. P.31-32.

[3] V.U. Zhylko, N.V. Klimashevich. Selection of cationic dyes and extraction conditions for photometric determination of higher carboxylic acids. Actual problems of chemistry: research and prospects: materials of the Second All-Ukrainian. scientific. conf., Zhitomir, March 16, 2018. Zhitomer. state un-t; editorial board: N. V. Kusyak [et al.]. Zhitomir. 2018. P.23.

[4] V.U. Zhylko. Ionic associates based on dyes - reagents for photometric determination of organic acids: PhD Thesis. Chem. Sciences: 02.00.02. Minsk. 2009. 125p. 